\title{
Push-out tests on demountable shear connectors of steel-concrete composite structures
}

\author{
A. Kozma ${ }^{a *}$, C. Odenbreit ${ }^{a}$, M.V. Braun ${ }^{a}$, M. Veljkovic ${ }^{b}$ and M.P. Nijgh ${ }^{b}$ \\ ${ }^{a}$ Research Unit of Engineering Sciences, University of Luxembourg, Luxembourg \\ ${ }^{b}$ Faculty of Civil Engineering and Geosciences, Delft University of Technology, Netherlands \\ *corresponding author, e-mail address: andras.kozma@uni.lu
}

\begin{abstract}
The deconstruction of steel-concrete composite structures in buildings and the later separation of the materials is a labour- and cost intensive work. The shear studs are welded on the steel beam and imbedded in the concrete deck and a large amount of cutting work becomes necessary. As a result, recycling is difficult and the potential for reusing entire elements is lost. The carbon footprint of composite structures could be decreased by application of the principles of "design for deconstruction and reuse".

This paper presents a desk top study and corresponding laboratory experiments on demountable shear connectors that facilitate recyclability and even provide the potential for reusing complete structural elements. In the Laboratory of Steel and Composite Structures of the University of Luxembourg 15 push-out tests have been carried out using different bolted connection systems suitable for multiple uses in order to verify their performance focusing on shear strength, stiffness, slip capacity, ductility and ability of demounting. The investigated systems included pre-stressed and epoxy resin injection bolts, solid slabs and composite slabs with profiled decking. The results showed that the tested demountable shear connections could provide higher shear resistance than conventional shear connections.
\end{abstract}

The critical failure mode is shear failure of the bolts, while there was no visible damage observed on the connected members. Most of the tested connections could fulfil the ductility requirement according to by Eurocode 4. The application of epoxy resin in the hole clearance resulted in lower slip capacity. The outcome provides an important basis for the justification of the forthcoming enhancement and validation of numerical models of the demountable shear connections.

The failure behaviour, the observed damages and the resulting ability of the elements for re-use are discussed in detail.

Keywords: Demountable shear connectors; push-out tests; metal decking; circular economy; shear capacity; experimental study.

\section{Introduction}

The circular economy is essential for a sustainable, resource-efficient and low-carbon future [1]. It means tracking materials throughout their life cycles so that their location is known and designing them in such a way that their future reuse is possible.

With proper considerations at the design stage, whole buildings or parts of it can be deconstructed and re-erected elsewhere. If the structural steel elements are not worn, yielded or corroded, they are ideal candidates for re-use with no melting and new hot rolling process. However, the deconstruction of steel-concrete composite structures in buildings and the later separation of the materials is a labour- and cost intensive work. The shear studs are welded on the steel beam and imbedded in the concrete deck and a large amount of cutting work becomes necessary. As a result, recycling is difficult and the potential for reusing entire 
elements is lost. The carbon footprint of composite structures could be decreased by application of the principles of "design for deconstruction and reuse".

This paper presents a part of results of a research project analysing reuse and demountability using steel structures and the circular economy. Within the framework of the European research project "REDUCE [RFCSGA-710040]", funded by RFCS, push-out tests have been conducted in order to determine the properties of the demountable shear connector systems that are studied in this research.

\section{Shear connectors for demountable composite beams}

\subsection{Reusability and demountability}

The application of the principles of the circular economy can take place on different levels. Crowther [2] differentiates the following levels for the built environment: material recycling, component remanufacture, component reuse and building relocation. This project aims to facilitate the component reuse and building relocation in the case of steelconcrete composite structures.

The ability to reuse building components depends on the ability to recover them. In current construction practice, after a building reaches the end of its life, usually demolition takes place, and the ability to reuse components is lost. The demolition process should be replaced by a deconstruction process, which is possible only if the building was designed for deconstruction.

In order to make steel-concrete composite structures demountable, bolted connections should replace the commonly used welded headed studs. Furthermore, the reusable parts should be designed to withstand repeated use.

\subsection{Demountable shear connectors}

Two types of demountable shear connectors for prefabricated composite flooring systems have been tested at the University of Luxembourg. Taking into account that the slab elements are meant to be reusable, L-shaped steel profiles are cast-in to provide edge protection to the elements.

\subsubsection{Friction bolts with cast in cylinders (P3)}

Shear connector type $\mathrm{P} 3$ consists of a cast-in steel cylinder welded to the L-profile, a top plate welded to the cylinder and a pre-tensioned M20 bolt with a grade 8.8 . This connection provides accessibility from the top of the slab through pockets in the concrete. The layout of the shear connector system is presented in Fig. 1. In the forthcoming, this shear connection type is referred to as "cylinder system".

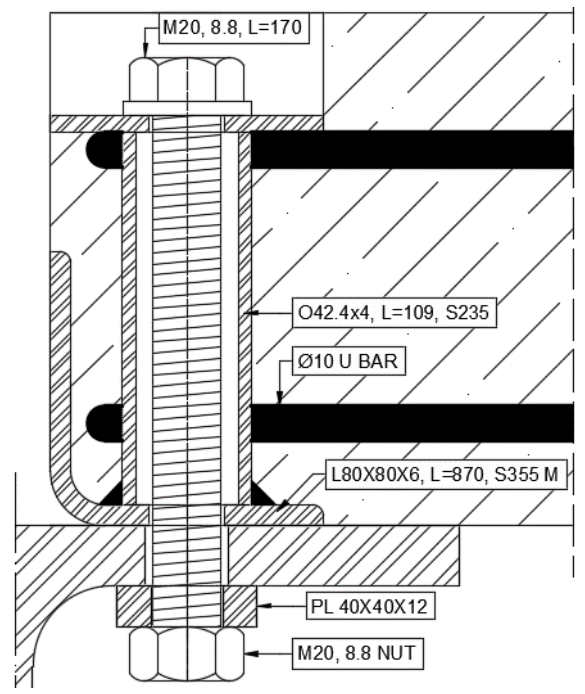

Fig. 1. Layout of the "cylinder system", P3

\subsubsection{Embedded coupler device (P15)}

Shear connector type P15 uses an embedded bolt coupler, an embedded bolt and a removable bolt placed from below.

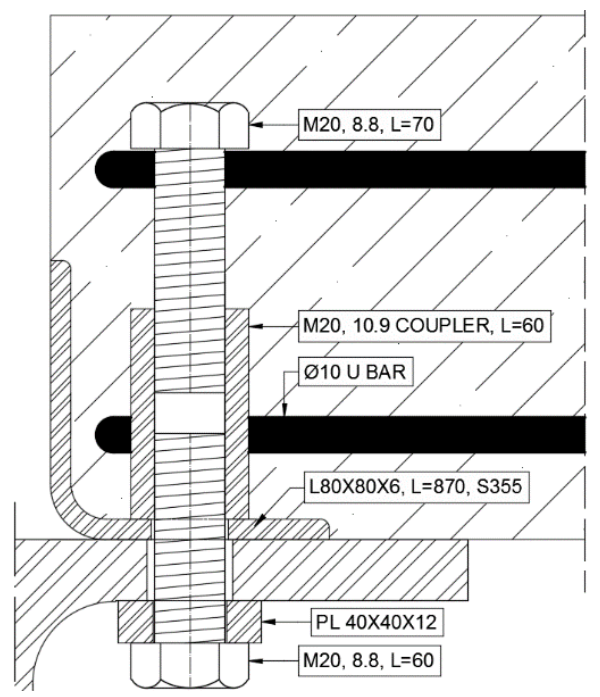

Fig. 2. Layout of the "coupler system", P15

The coupler has a grade of 10.9 , while the bolts are made of 8.8 material. The reason behind the higher material strength of the coupler is, that this way we can ensure that if the threads are damaged, then the damage will occur in the bolt, which is replaceable, and not in the coupler, which is not. Fig. 2 shows the layout of the shear 
connector system. In the forthcoming, this shear connection type is referred to as "coupler system”.

Two variants of this connection type were developed. The two variants are mostly identical, but P15.1 uses pre-tensioned bolts and P15.2 uses epoxy resin injected bolts i.e. the gap between the bolt and the bolt-hole is filled with resin.

\section{Push-out tests}

\subsection{Tests specimens}

A total of 15 push-out test specimens have been fabricated with a geometrical layout similar to the one recommended by Eurocode 4 [3]. Five different test configurations were fabricated, and for each configuration, three identical specimens were tested. Three series used solid slabs, and two used ComFlor ${ }^{\circledR} 80$ metal decking. The overview of the test parameters is presented in Table 1 .

Table 1. Test parameters

\begin{tabular}{|c|c|c|c|}
\hline Series & $\begin{array}{c}\text { Shear } \\
\text { connector }\end{array}$ & Slab type & Remark \\
\hline P3.1 & $\begin{array}{l}\text { Cylinder } \\
\text { system }\end{array}$ & Solid & \\
\hline P3.2 & $\begin{array}{l}\text { Cylinder } \\
\text { system }\end{array}$ & CF80 & $\begin{array}{c}\text { Galvanized } \\
\text { elements }\end{array}$ \\
\hline P3.3 & $\begin{array}{l}\text { Cylinder } \\
\text { system }\end{array}$ & CF80 & \\
\hline P15.1 & $\begin{array}{l}\text { Coupler } \\
\text { system }\end{array}$ & Solid & \\
\hline $\mathrm{P} 15.2$ & $\begin{array}{c}\text { Coupler } \\
\text { system }\end{array}$ & Solid & $\begin{array}{c}\text { Injection } \\
\text { bolts }\end{array}$ \\
\hline
\end{tabular}

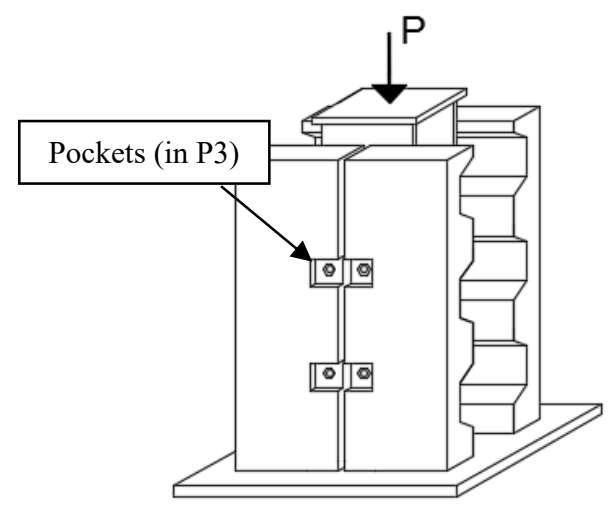

Fig. 3. The test setup

Fig. 3 presents the schematic view of the test setup. Each specimen consisted of 4 prefabricated slab elements and an HE 260B steel beam. As shown in Table 2, in all cases $\phi 8 / 75$ reinforcement was applied with a material grade of B500 B. The solid slabs had two layers of reinforcement in both directions, while the slabs with metal decking had one layer. The concrete strength was measured at the age of 28 days on standard cubic specimens. The configuration of the push-out test specimens is shown in Fig. 4 and Fig. 6.

Table 2. Concrete strength and reinforcement

\begin{tabular}{ccc}
\hline Series & $\begin{array}{c}\text { Concrete cubic } \\
\text { strength } \\
\mathbf{f}_{\mathbf{c}, \mathbf{2 8}}\left[\mathbf{N} / \mathbf{m m}^{2}\right]\end{array}$ & Reinforcement \\
\hline P3.1 & 59.4 & 2 layers $\phi 8 / 75$ \\
P3.2 & 59.4 & 1 layer $\phi 8 / 75$ \\
P3.3 & 59.4 & 1 layer $\phi 8 / 75$ \\
P15.1 & 44.3 & 2 layers $\phi 8 / 75$ \\
P15.2 & 44.3 & 2 layers $\phi 8 / 75$ \\
\hline
\end{tabular}
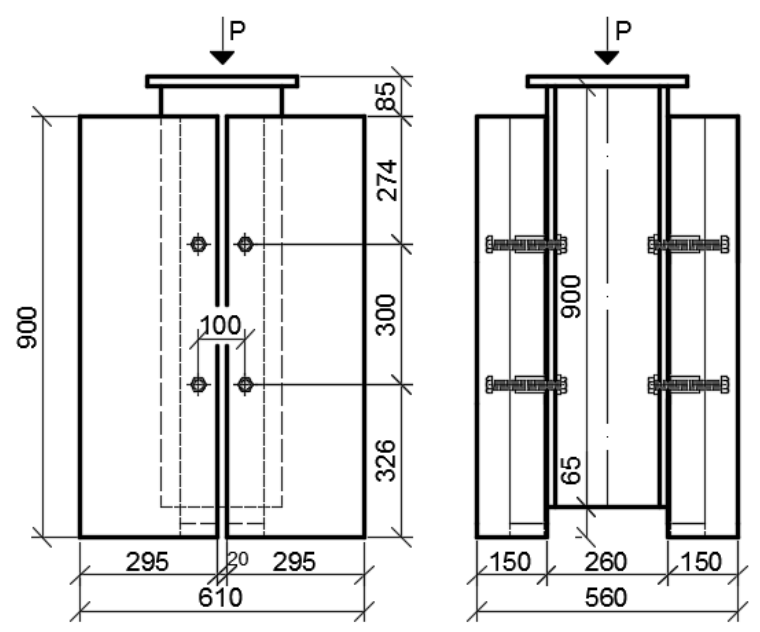

Fig. 4. Configuration of series P15.1

For the cylinder system (P3), pockets in the concrete were created (see Fig. 3) with the help of polystyrene blocks which were removed after the concrete had hardened. As shown In Fig. 5, the metal decking was shorter than the concrete part, enabling the slab to have full depth like a solid slab without metal decking in the vicinity of the shear connectors.

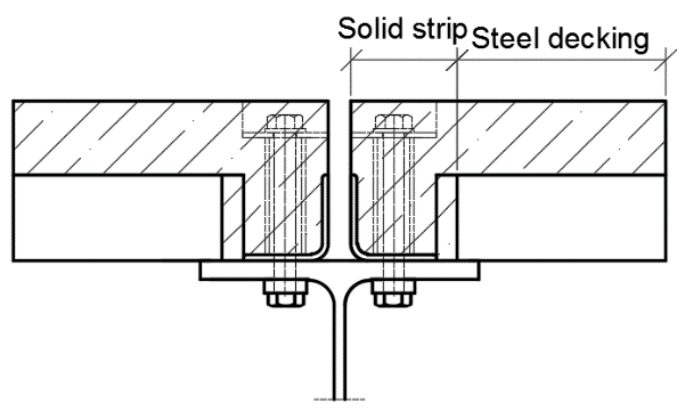

Fig. 5. Solid strip and steel decking 

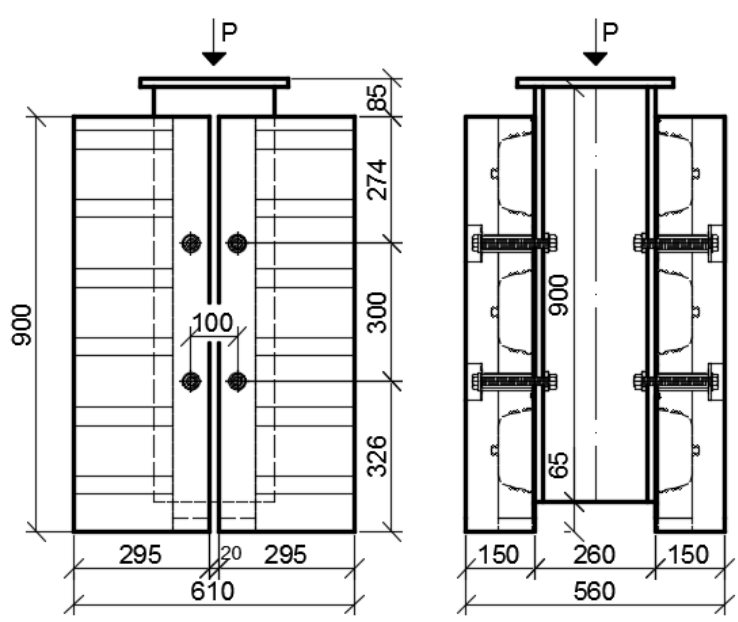

Fig. 6. Configuration of series P3.3

The bolt holes in the flange of the steel beam have been oversized and had a diameter of 24 $\mathrm{mm}$ in order to allow for fabrication and construction tolerances. The application of resin in the bolt holes allowed larger tolerances, thus $6 \mathrm{~mm}$ clearance was applied in the series P15.2. In test series P3.2, the steel beam, the L-profile and the bolts were galvanized.

The pre-tensioning was applied using the combined method defined by EN 1090 [4]. Different levels of pre-tension were analysed. The applied force was assessed by complementary tests defined by EN 1090 Annex $\mathrm{H}$. Table 3 summarises the applied pre-tension forces in the different test series.

Table 3. Applied pre-tension forces

\begin{tabular}{cc}
\hline Series & $\begin{array}{c}\text { Pre-tension } \\
\text { force }[\mathbf{k N}]\end{array}$ \\
\hline P3.1 & 100 \\
P3.2 & 120 \\
P3.3 & 120 \\
P15.1 & 176 \\
P15.2 & 0 \\
\hline
\end{tabular}

\subsection{Tests setup, measurements and procedure}

One day before the tests the specimens were placed into a mortar bedding. The tests were conducted using a hydraulic jack with a load capacity of $1000 \mathrm{kN}$. During the test, belts were put around the specimens to prevent the parts from falling apart once the continuity was lost (see Fig. 7).

During test conduction, the force in the hydraulic jack and the displacements were continuously monitored.

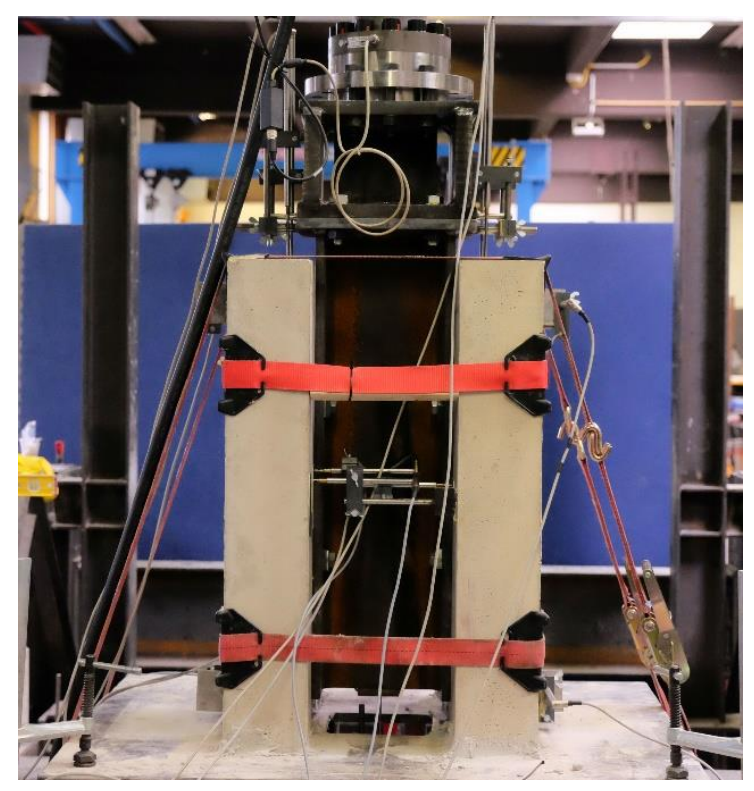

Fig. 7. Test setup

For each specimen 15 displacement transducers (LVDTs) were employed to measure the (i) relative vertical displacement between the steel beam and the slab elements, (ii) the vertical displacement of the beam measured to the ground floor, (iii) the transversal separation between the steel beam and the slab elements, (iv) the relative horizontal displacement between the adjacent slab elements and (v) the relative horizontal displacement between the slabs on the different flanges of the beam. Fig. 8 shows the layout of the applied displacement transducers.
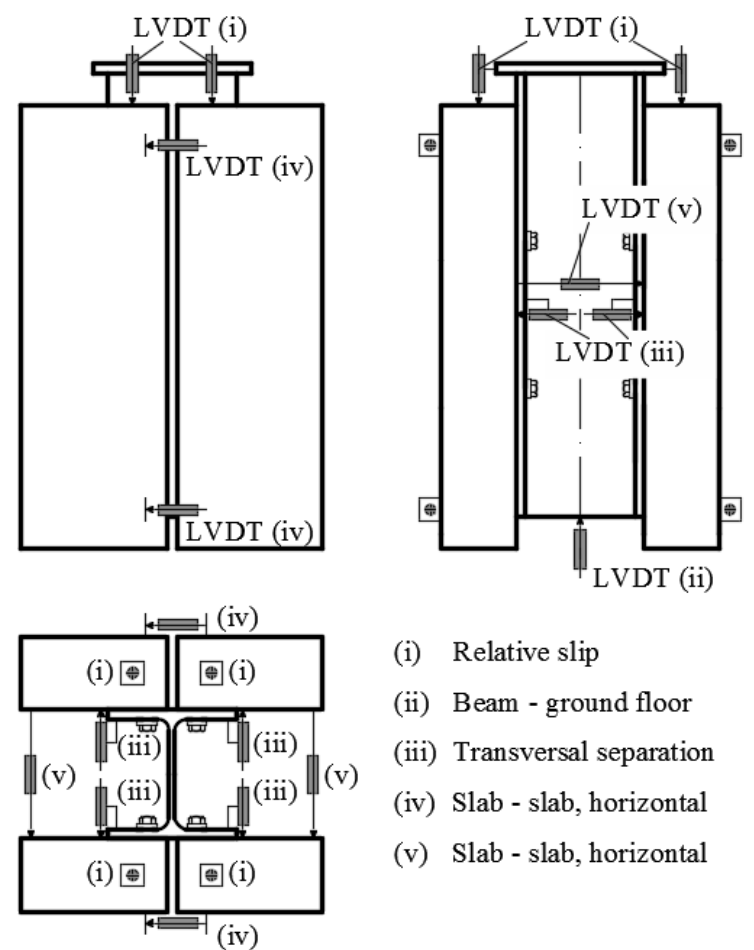

(i) Relative slip

(ii) Beam - ground floor

(iii) Transversal separation

(iv) Slab - slab, horizontal

(v) Slab - slab, horizontal

Fig. 8. Layout of the LVDTs 
The loading procedure for standard push-out tests includes 25 load cycles between $5 \%$ and $40 \%$ of the expected failure load. The applied loading regime is illustrated in Fig. 9. In order to determine the failure load, the first test (LR1) of each series was conducted without cycles. In the second (LR2) and third tests of each configuration, the cycles were performed between $5 \%$ and $40 \%$ of the previously measured failure load. During the third tests (LR3), in addition to the 25 cycles, several unloading - reloading cycles were performed after $0.5 \mathrm{~mm}-1 \mathrm{~mm}$ increments in the relative slip in order to determine the actual stiffness at larger displacements.

The specimens were loaded in a force controlled mode with a $20 \mathrm{kN} / \mathrm{min}$ load rate until the first slip had occurred. Afterwards, the loading procedure continued in a displacement controlled mode with a speed of $0.5 \mathrm{~mm} / \mathrm{min}$.

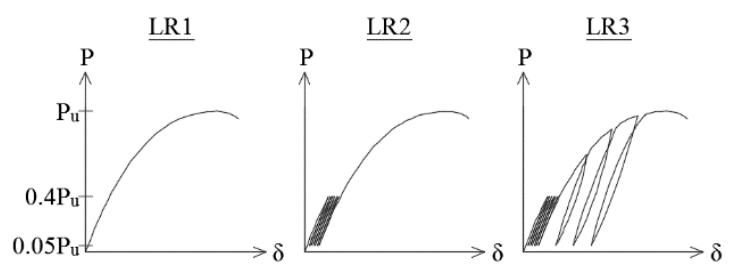

Fig. 9. Loading regime

The applied bolts had in all cases at least 20\% overstrength compared to their characteristic strength value, so the $1000 \mathrm{kN}$ capacity of the hydraulic jack was not sufficient to cause failure. Therefore, during load regime 1 (LR1), the tests started with 8 bolts until the total load level of $500 \mathrm{kN}$. Then the specimens were unloaded, and the 4 bolts in the upper row had been removed. Afterwards, the specimens were tested with only the four lower bolts. In LR2 and LR3, the 4 upper bolts were removed before testing. During the tests, LVDTs (iv) (see Fig. 8) measured the tilting of the slab elements which was between 0.16 and 0.74 degrees in all cases. The maximum transverse separation at failure measured by LVDTs (iii) was $0.3 \mathrm{~mm}$. The maximum relative horizontal displacement measured by LVDTs (v) was $1.1 \mathrm{~mm}$. Based on these measurements it had been concluded, that the setup with 4 bolts was rated as suitable for push-out tests.

\subsection{Cylinder system (P3)}

\subsubsection{First assembly}

The load-displacement curves of the cylinder system with solid slabs (P3.1) are shown on
Fig. 10, where the relative slip corresponds to the average measured slip between the steel beam and the four slab elements. Due to the pretensioning, the initial stiffness of the system was high $(250 \mathrm{kN} / \mathrm{mm})$ in the early load stages until the friction resistance had been overcome at a load level of $26 \mathrm{kN} \mathrm{/} \mathrm{shear} \mathrm{connector.}$ Afterwards, the stiffness decreased significantly to $15 \mathrm{kN} / \mathrm{mm}$. There was only minor nonlinear behaviour observed. In all cases, shear failure of the bolts occurred at an average load level of $141 \mathrm{kN} /$ shear connector.

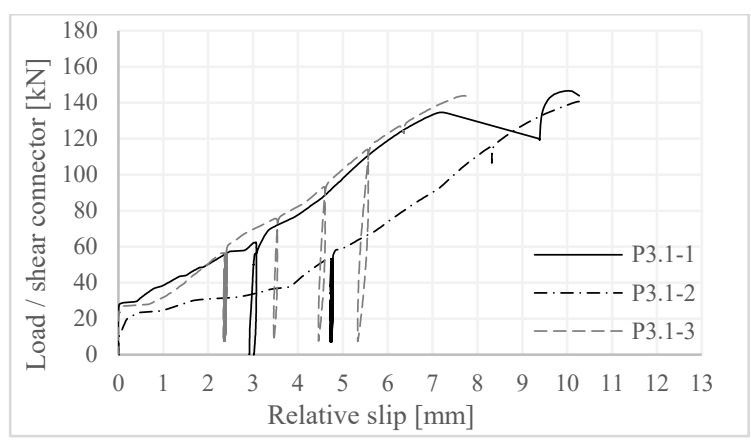

Fig. 10. Cylinder system with solid slabs

The failure happened in a very brittle way with no or minor descending branch between 7 and $10 \mathrm{~mm}$ relative slip. The load-displacement curves of specimens P3.1-1 and P3.1-3 are in a good agreement, while P3.1-2 shows larger slip capacity. This is due to the fact that the hole clearance was not deducted from the presented slip values, and the bolts have been positioned randomly inside the holes. In the case of P3.1-1, the sudden jump in the curve at $7 \mathrm{~mm}$ slip is caused by the failure of one bolt which failed earlier than the others.

As shown in Fig. 11, minor damages were observed on the elements of the specimens: bearing failure of the L-profiles, and the thread shapes were visible on the bearing surface of the holes of the steel beam.
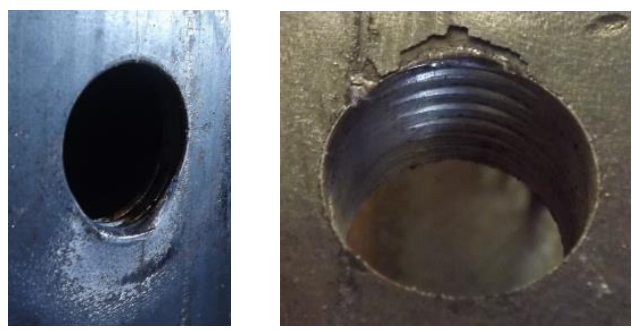

Fig. 11. Observed damages (P3.1-1)

The load-displacement curves of the specimens with metal decking are illustrated in Fig. 12 and Fig. 13. 


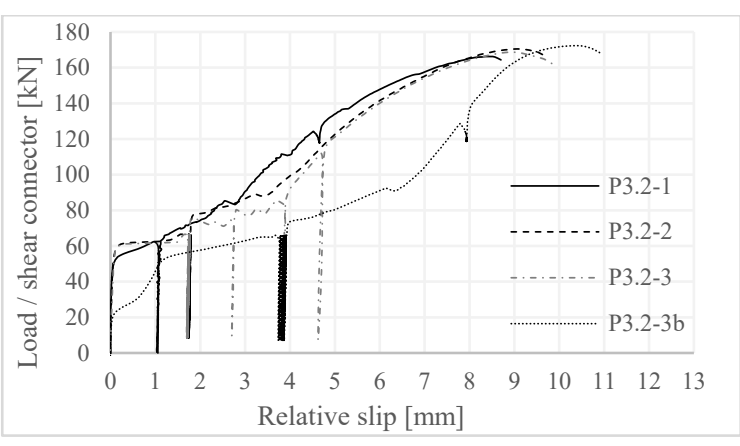

Fig. 12. Cylinder system with metal decking and galvanized elements

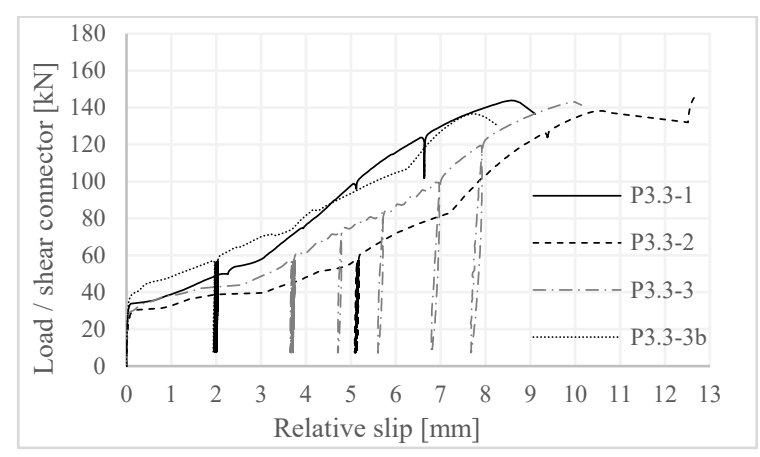

Fig. 13. Cylinder system with metal decking

In the case of series P3.2 and P3.3, the initial stiffnesses were $500 \mathrm{kN} / \mathrm{mm}$ and $300 \mathrm{kN} / \mathrm{mm}$ respectively. In the case of the galvanized specimens (P3.2) the first slip occurred at a load level of $57 \mathrm{kN} /$ shear connector, while in the case of specimens with no surface finish (P3.3), the friction resistance was $31 \mathrm{kN} /$ shear connector. After the first slip occurred the stiffness decreased to $15 \mathrm{kN} / \mathrm{mm}$.

It can be noticed that for the bolts of series P3.2 the strength is higher $(168 \mathrm{kN})$ when compared to the results of P3.3 $(143 \mathrm{kN})$. This is in agreement with the results of the uniaxial tensile tests that had been conducted on 4 bolts of each type resulting in mean values of the ultimate strengths of 1045.6 $\mathrm{MPa}$ and $948.7 \mathrm{MPa}$ respectively.

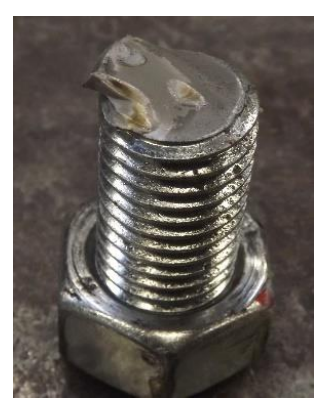

Fig. 14. Failure surface of a bolt (P3.2-1)
All bolts failed in shear and similar minor damages were observed as in series P3.1.

\subsubsection{Re-assembly after failure}

In order to assess the effect of these minor damages on the reusability, the most heavily loaded specimens (P3.2-3 and P3.3-3) were reassembled with new bolts and the tests were repeated. The results of these tests are indicated as P3.2-3b and P3.3-3b in Fig. 12 and Fig. 13 respectively. In the second tests, the failure mode was again bolted shear leading to similar resistance values as in the case of the original tests. However, lower friction resistance and larger relative slip were observed in the case of the galvanized specimen (P3.2-3b).

\subsection{Coupler system (P15)}

The load-slip curves of the tests of the coupler system with pre-tensioned bolts are presented on Fig. 15. The initial stiffness was 70 $\mathrm{kN} / \mathrm{mm}$. The first slip occurred at a load level of $50 \mathrm{kN} /$ shear connector. Then, after a slip of 2 $\mathrm{mm}$, the stiffness reduced to $30 \mathrm{kN} / \mathrm{mm}$. In all cases, a brittle shear failure of the bolts occurred at an average load level of $142 \mathrm{kN} /$ shear connector.

As shown in Fig. 16, no bearing failure occurred in the L-profile. However, the shape of the threads could be observed in the bearing surface of the holes of the steel beam.

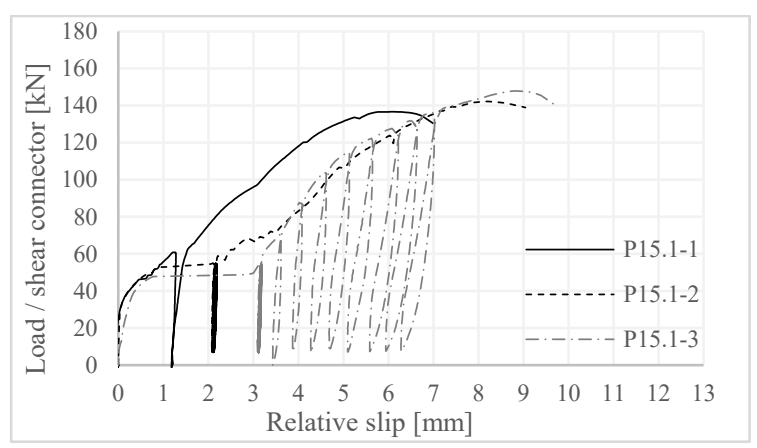

Fig. 15. Coupler system with pre-tensioned bolts
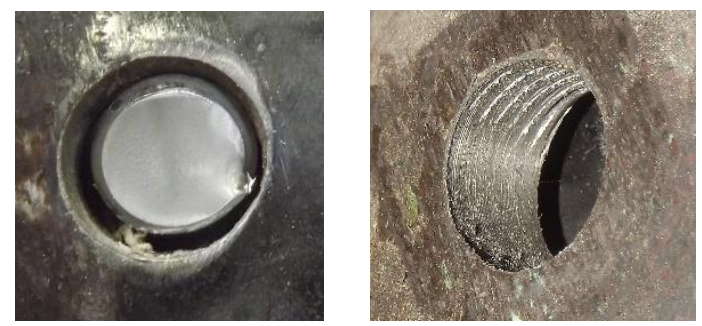

Fig. 16. Observed damages (P15.1-1) 
Fig. 17 presents the results of the tests on resin injected bolts. The load-slip curves have three parts: an initial part with a stiffness of 100 $\mathrm{kN} / \mathrm{mm}$ until the load level of $50 \mathrm{kN}$, the second part with a stiffness of $30 \mathrm{kN} / \mathrm{mm}$ until the load level of $110 \mathrm{kN}$ and the final part with a stiffness of $5 \mathrm{kN} / \mathrm{mm}$ until failure. The shear failure of the bolts occurred at an average load level of 131 $\mathrm{kN}$. As the resin in the bolt holes prevented the slippage of the bolts, the curves are in a good accordance despite the varying loading regime. Bolt shear was the only observed damage on the specimens. Fig. 18 shows a bolt after failure. The resin remained intact during the test. Because of the threaded shape of the resin, the use of a wrench was necessary for the removal of the bolt head from the steel beam.

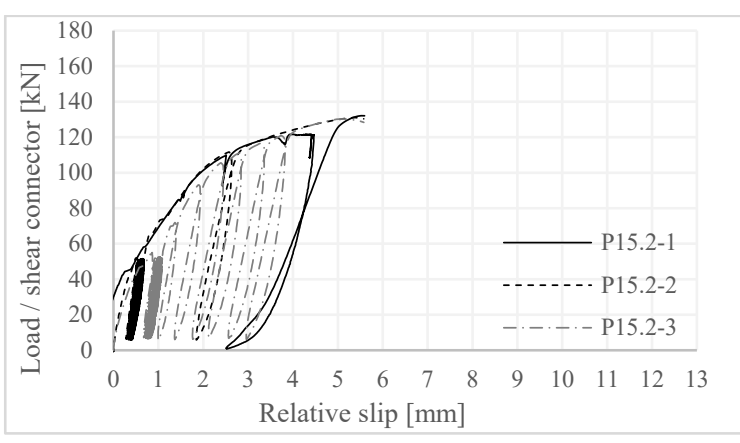

Fig. 17. Coupler system with resin injected bolts

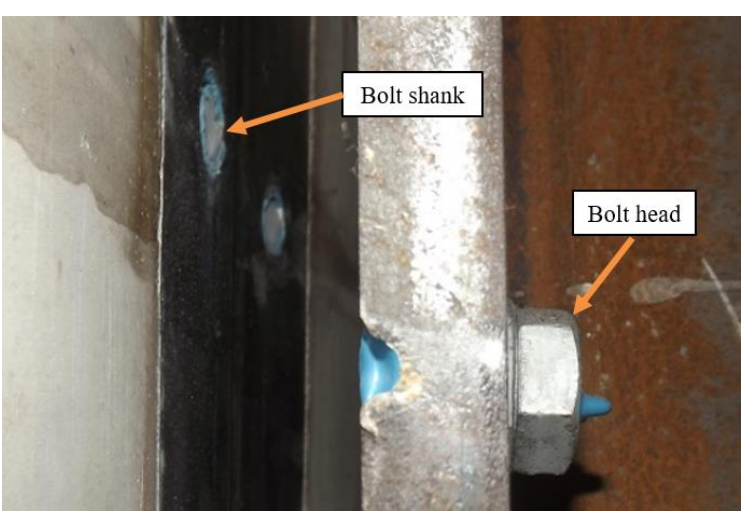

Fig. 18. Sheared bolt after failure (P15.2-1)

\section{Discussion}

\subsection{Strength, stiffness and ductility}

The highest strength $(168 \mathrm{kN})$ was measured in tests series P3.2 which consisted of the cast-in cylinders and galvanized elements. However, this is the result of the higher material strength of the bolts. In all cases, the shear failure of the bolts was the governing failure mode. The cylinder system (P3) produced higher resistances, $150 \mathrm{kN}$ in average, than the coupler system (P15) which had $137 \mathrm{kN}$ on average. The cylinder system (P3) had in all cases larger slip capacity than the coupler system (P15).

In almost all cases, the load-slip curves showed, that the slip capacity has a high sensitivity on the position of the bolts inside the holes. The only exception was series P15.2 where the epoxy resin was injected into the bolt hole. This effect will be further investigated with the help of numerical simulations.

As shown in Fig. 19, the specimen with metal decking behaved similarly to the specimen with solid slabs. This is due to the fact that no concrete damage was observed during the tests.

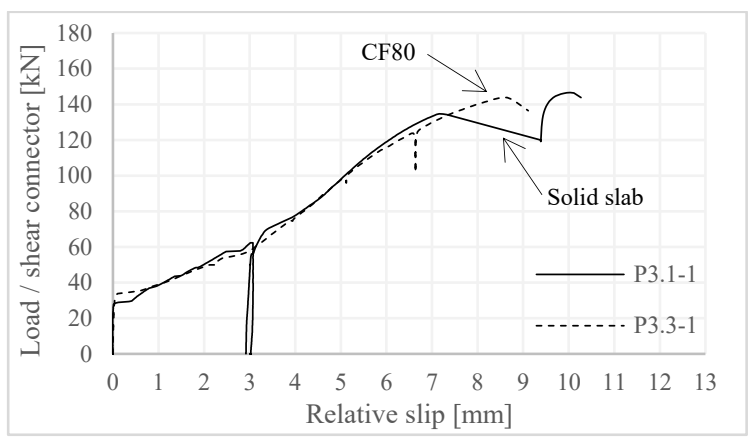

Fig. 19. Comparison of solid slab with metal decking

Due to the pre-tensioning, the initial stiffness of the specimens was high $(250-500 \mathrm{kN} / \mathrm{mm})$, but after the friction resistance was overcome the stiffness reduced to $15 \mathrm{kN} / \mathrm{mm}$, which is very low compared to the stiffness of a welded shear connector.

Eurocode 4 considers a connector as ductile if the characteristic slip capacity is at least $6 \mathrm{~mm}$. It defines the characteristic slip as the maximum slip measured at the characteristic load level, which is the $90 \%$ of the failure load after failure. Most of the tested configurations had larger deformation capacity than $6 \mathrm{~mm}$, except series P15.2. However, after the maximal load was reached, the specimen failed earlier than the $10 \%$ load drop could have happened. Furthermore, contrary to traditional shear connectors where the maximal load is usually reached after 1-2 mm of relative slip, the tested demountable shear connection systems showed monotonously increasing load-slip curves and reached their maximal load at slip values of 5-10 mm. Only minor descending branch was observed after failure. As a consequence, the questions of the ductility and the characteristic strength is still open for discussion. 


\subsection{Friction resistance}

The tests showed that the specimens with no surface finish had a friction coefficient of 0.26 , while the galvanized specimen had 0.48 . However, after re-assembly of the failed specimens, the galvanized specimen's friction coefficient was reduced to 0.23 , while there was no change in the case of the specimen with no surface finish (see Table 4). This reduction of friction coefficient could be explained by the flattening of the surface asperities during the first test.

Table 4. Preload and friction resistance

\begin{tabular}{cccc}
\hline Series & $\begin{array}{c}\text { Preload } \\
{[\mathbf{k N}]}\end{array}$ & $\begin{array}{c}\text { Friction } \\
\text { resistance } \\
{[\mathbf{k N}]}\end{array}$ & $\begin{array}{c}\text { Friction } \\
\text { coefficient } \\
{[-]}\end{array}$ \\
\hline P3.1 & 100 & 26 & 0.26 \\
P3.2 & 120 & 57 & 0.48 \\
P3.2b & 120 & 27 & 0.23 \\
P3.3 & 120 & 31 & 0.26 \\
P3.3b & 120 & 33 & 0.27 \\
P15.1 & 176 & 46 & 0.26 \\
\hline
\end{tabular}

\subsection{Demountability and reusability}

In load regime 1 (LR1), the specimens were loaded until $500 \mathrm{kN}$, then unloaded, and the four upper bolts have been removed. The successful removal of these bolts proved the systems demountability. Specimens P3.2-3 and P3.3-3 were re-assembled after failure with new bolts. Afterwards, they were loaded until failure. Their second test showed similar behaviour to their original tests in the means of strength, stiffness and slip capacity. Because the failure occurs in the bolts and not in the connected members, the developed composite flooring systems are robust and therefore adequate for reuse

\section{Conclusion}

The results of 15 push-out tests on demountable shear connectors have been presented. Based on these results, the structural behaviour of bolted connections was assessed. the following conclusions are made:

1. The tested pre-tensioned demountable shear connectors show full interaction before the friction resistance is overcome.

2. The developed solutions are robust and adequate for reusable composite flooring systems.
3. The bolt position inside the hole has an influence on the load-slip curves.

4. Slabs with metal decking can provide similar results to solid slabs if the slabs have full depth in the vicinity of the shear connectors.

5. With the application of epoxy resin, larger tolerances can be allowed without compromising the load-bearing capacity where the execution of large deck components makes it necessary.

\section{Outlook}

Composite beam tests will be carried out with the developed connections. The test bending resistances will be compared to the calculated plastic bending resistance of the beams using the partial shear connection rules in Eurocode 4 and also to the elastic stiffness assuming full composite action.

The tested demountable connections will be analysed by finite element models of various complexity. Parametric studies will be done analysing the effect of the bolt position on the stiffness of a composite beam.

\section{Acknowledgement}

The research leading to these results is a part of a common project of Steel Construction Institute, University of Luxembourg, University of Bradford, Lindab, Tata Steel, Bouwen met Staal, Delft University of Technology and AEC3. The project has received funding from the Research Fund for Coal and Steel under grant agreement No 710040.

\section{References}

[1] Ashby, MF, Balas, DF, and Coral, JS. Materials and sustainable development. Oxford: Butterworth-Heinemann. 2016;211-241.

[2] Crowther, P. Design for disassembly - themes and principles. RAIA/BDP Environment Design Guide, August 2005 Australia. http://doi.org/10.1115/1.2991134.

[3] EN1994-1-1, Eurocode 4: Design of composite steel and concrete structures - Part 1-1: General rules and rules for buildings. 2004.

[4] EN1090-2, Execution of steel structures and aluminium structures - Part 2: Technical requirements for steel structures. 2008. 